\title{
8. Certification: implementation challenges in private-social partnerships
}

\author{
Joanna Vince
}

\section{INTRODUCTION}

Collaboration between the actors of the three social mechanisms or modes of governing (community, market and the state) can increase efficiency, flexibility, and innovation amongst state and non-state actors (Hartley, Sørenson, and Torfing 2013; Koppenjan and Klijn 2004; Sørenson 2012). The relationships and types of governance arrangements that result from the modes include: market and the state (private-public); community and the state (social-public); market and community (private-social); and networks (private-public-social) (Howlett and Ramesh 2015; Steurer 2013). Collaborative governance literature has focused on the private-public, social-public relations, privatepublic-social (Ansell and Gash 2008; Howlett and Ramesh 2016; Rhodes 1997). However, there has been less emphasis on collaborative governance in private-social relationships due to the absence of government and the public realm in the governance arrangements (Cashore 2002b; Howlett and Ramesh 2016).

Third party assessment and certification organizations, also known as non-state market driven NSMD actors (Auld et al. 2009; Cashore 2002a, see also Cashore, Chapter 10 in this volume), are involved in private-social partnerships that become a form of hybrid governance (Lemos and Agrawal 2006; Vince and Haward 2017; Vince and Haward 2019). External third party certification organizations that assess resource management certify industry against high environmental standards and aim to give the consumer the confidence that they are buying and consuming environmentally sustainable produce (Gale and Haward 2011). State-based governance has traditionally dominated in the management of natural resources. This regulatory framework, however, has experienced difficulties and challenges with the implementation of sustainable, conservation measures. As a result, alternative tools and approaches, 
including external third party assessment and certification systems, have been developed to address perceived regulatory failure, including economic and community based management.

These approaches step outside state-based governance and address market and consumers directly through product certificates and ecolabels (Potts and Haward 2007). Certification and labelling initiatives have been seen as 'tuning the market' (Teisl, Roe, and Hicks 2002) while encouraging industry best practices that influence shareholders and the market. Moreover, they can add another layer of legitimacy for community groups in providing their social license to operate (SLO). Although self-regulatory industry measures, policies and standards can also be effective in environmental governance, they are less so than those developed by third party certification organizations (Abbott 2012). Mutual interdependence of non-state and market-based actors is a dominant feature of the private-social relationship. The state can increase the legitimacy and trust of the third party certifiers by not being involved, and has the ability to change this through regulatory measures if the community's trust in the private-social relationship diminishes in any way.

This chapter begins by examining the collaborative efforts between third party assessment and certification organizations, other non-state actors and the state. It then discusses how community acceptance and trust is a critical condition in the collaborative process. The lack of community support and trust of industry and certifiers, and the influence of powerful non-state actors such as the media and environmental non-governmental organizations (NGOs) can influence the level of trust. While actors do not necessarily need to get along to be involved in a collaborative process (Ansell and Gash 2008), restraint from any form of collaboration can be seen as a collaborative failure.

The chapter then looks at the Aquaculture Stewardship Council (ASC) as an example of a third party certifier and its role in the case study on Australian salmonid aquaculture. The salmon aquaculture industry in the state of Tasmania is Australia's most valuable fishery, increasing by 194 percent in value in the last decade (ABARES 2015). This sector has been heavily influenced by the market through shareholder expectations and the large economic benefits to industries and the state. Regulation of salmonid aquaculture through public policies and law is still a part of the overall linkage between state and the community, and the state and the market, but it is noticeably absent from the private-social relationship (Vince and Haward 2017; Vince 2018). It therefore is an illustrative case of how trust is a critical factor in steering the collaborative process where third party certifiers are involved. 


\section{HYBRID GOVERNANCE AND COLLABORATION}

Governance in the management of natural resources has become increasingly complex over the last few decades. International and national regulatory approaches have focused on and encouraged the implementation of ecosystem-based management and policy integration, however, sector-based arrangements continue to dominate (see for example Haward and Vince (2008) and how this has occurred in ocean governance). While integration (Vince 2015) and collaboration (Clarke et al. 2013) across and between different sectors and jurisdictions (vertical and horizontal) has been difficult to achieve, this process has revealed new actors and relationships in natural resources management that do not fit the traditional top-down regulatory approach to governance. Importantly, it has demonstrated that the sectors themselves have increasing challenges with market and shareholder expectations; their relationships with non-state actors and the wider community; and the implementation of ecosystem-based management strategies and sustainable practices.

This has resulted in a movement from regulatory governance arrangements to a hybrid form of governance which is better adapted to complex arrangements and relationships, where multiple levels and sectors are involved (Gale and Haward 2011). In a hybrid governance arrangement, governmental actors are one of many sources in the decision-making process. Others include non-state actors such as civil society organizations and NGOs, fishermen's cooperatives, and private businesses (Alexander, Andrachuk, and Armitage 2016). The hybrid form of governance utilizes these relationships and gathers support from groups in ways that the traditional state-centered approach is unable to do so through the establishment of shared interests and values. Each actor has diverse interests, capabilities and their expectations of accountability can vary.

These hybrid arrangements are present in co-management, private-public partnerships and private-social partnerships (Bäckstrand 2008; Lemos and Agrawal 2006). They each have similar characteristics: 'non-hierarchical steering' (Bäckstrand et al. 2010); they are voluntary to join; and market driven (Auld et al. 2009). Unlike in public-private partnerships, the community in private-social partnerships is a powerful actor and it is the relationship between the market and the community that has allowed new actors to participate and steer decision making.

Lemos and Agrawal (2006) find that the different combinations of hybrid partnerships illustrate the 'fast changing nature' of environmental governance. Furthermore:

The emergence of these hybrid forms of environmental governance is based upon the recognition that no single agent possesses the capabilities to address the multiple 
facets, interdependencies, and scales of environmental problems that may appear at first blush to be quite simple. (Lemos and Agrawal 2006)

These hybrid arrangements can also create challenging conditions with regard to the role and responsibilities of the actors involved; questions of accountability, check and balances, and lack of transparent information (Alexander et al. 2016). Often actors within hybrid arrangements volunteer, are co-opted or mandated to self-regulate. The state takes on a subordinate, supporting or parallel role or a 'shadow of hierarchy' (Thomann 2017).

Third party non-state actors have long been active in debates over sustainable resource exploitation. These actors include producer-based self-certified approaches through to rigorous third party independent certification, using processes external to, and separate from, the producer/industry. With the development of third party assessment and certification of sustainable resources management, these actors have become significant players in rule making (Vandergeest, Ponte, and Bush 2015) and governance (Foley and Hébert 2013).

Third party certification bodies have taken over the regulatory roles of the state because it does not have the capacity to effectively or efficiently develop, deliver and monitor the standards that industry and the community are seeking in sustainable environmental management (Howlett and Ramesh 2016). That is not to say the state is completely absent from decision making over resource management-it provides, inter alia, criminal, environmental and industrial laws and guidelines, site licenses, and in some cases it even subsidizes industry activities. But the traditional hierarchical form of governance cannot provide the services of third party certification organizations. This lack of state capacity is not unique to certification and also being observed in other aspects of resources management (see Vince and Nursey-Bray 2016). Painter and Pierre (2005: 12) put forward that "if 'governance' ... is used to describe practices of consultation, coordination and bargaining across boundaries, then it is here that we should look for sources of policy capacity." However, they also acknowledge that policy capacity can exist outside of the state. It is here that third party certification organizations fill a void in the regulatory gap that the state has difficulty providing.

Third party certification organizations can be classified as being part of 'private co-regulation' (Steurer 2013), 'private governance' (Gulbrandsen and Auld 2016), and/or as being 'network-market/market-network' actors (Howlett and Ramesh 2016). While it is voluntary for industry to be certified, once the certification process is completed industry must adhere to binding rules (Bernstein and Cashore 2007) and third party certifiers must constantly review and uphold these rules as a governing body. To do this, collaboration 
and networking become key roles for the organizations in co-regulation (Steurer 2013). However,

one should not overlook that the steering mechanisms at work here are, again, strongly aligned with the market mode of governance, that is, with business concerns about brand reputation, competitiveness and the urge to ease or pre-empt potentially costly civil regulation and hard governmental regulation. In this sense, co-regulation often represents network governance in the (sometimes hardly visible) shadows of both markets and hierarchies. (Steurer 2013: 397)

The 'private' part of the private-social partnership, the market, is essential for the operation, legitimacy and continuity of third party certification organizations. According to Auld (2010) certification schemes have four features: logos or ecolabels targeted at the consumer; inspection and monitoring of the accreditation standards; governance structures and procedures that include 'rules for membership, decision-making, setting and revising standards, accrediting auditors, and addressing and resolving disputes'; and social and environmental standards measuring the impacts of production and life cycle of the product.

To be third party certified, companies voluntarily apply to be assessed. Independent certifiers then assess and certify the product against a set of standards. There is a fine line in establishing these standards - if they are too low the objectives are meaningless (Naylor, Eagle, and Smith 2003); if they are too high participation rates tend to be low and the scheme becomes unattainable. The companies are then audited for their compliance with the standards (Bush et al. 2013). Standards provide a base for assessment assuring that the activity can be continued indefinitely at a reasonable level; they maintain and seek to maximize ecological health and abundance; and they ensure that the company is managed and operated in a responsible manner, in conformity with local, national and international laws and regulations. In addition, standards can help assure present and future economic and social options and benefits while activities are conducted in a socially and economically fair and responsible manner (Potts and Haward 2007).

The certified company can then apply the eco-label provided by the scheme to market their product. They can also be used to distinguish their product from others in the market. Labelling is quick, efficient and more stringent than regulatory provisions (McLaren 2011; Naylor et al. 2003). The eco-labels themselves are marketable objects and can be defined 'by rules of exclusivity' through the marketization of social and environmental values (Foley and Hébert 2013).

The certification process provides the 'strongest regulation' and 'political legitimacy' through the social acceptance by the broader community of the rules and standards (Bernstein and Cashore 2007; also see Cashore, Chapter 
10 in this volume). The legitimacy of third party certifiers can be removed at any time if the community decides not to accept the standards or organization. This can be achieved when the community decides to keep or withhold social license to operate, affecting not only the third party certification organizations but also industry. The community can also influence the state to step in and regulate. State involvement would most likely only occur in the most critical of times such as a breakdown of the private-social relationship due to corruption or ineffectiveness of standards. For the majority of the time, as Auld et al. (2009: 189) put it, "authority is granted through the market's supply chain." Certification schemes can therefore be considered "new markets of governance" through their organizational set up, consultancy services and contractual arrangements (Foley and Hébert 2013).

\section{COMMUNITY ACCEPTANCE AND TRUST}

This 'social' part of the private-social partnership, the community mode of governance is made up of a multitude of components (Taylor 1982). These include local communities, broader/wider communities, the international community, non-state actors such as the media, and NGOs. In private-social partnerships, this is where the consumers are located and they have the ability to steer the market. The influence of the community has increased through hybrid and network arrangements and/or engagement in policy and decision-making, most notably through its ability to impose or remove social license. SLO is an intangible, unwritten and impermanent social contract between industry and social groups (Parsons and Moffat 2014). Vince (2018) argues that SLO is not a formal or legal 'license' that can be contested. The community has the power to give or withhold social license by utilizing their shared interests and values (Alexander et al. 2016) in their approach to an issue or activity. To maintain their legitimacy, industry actors recognize the importance of holding on to their social obligations beyond their regulatory requirements. SLO is also not a precondition to carry out a legal activity, but it does assist in gaining legal approval if the situation is legally or politically uncertain (Haward et al. 2013). Having both social and legal approval through a social license to operate provides industry legitimacy for their activities.

Legitimacy is referred to as the 'minimum' requirement for achieving social license. Community acceptance and trust offers stronger and higher levels of social license (Parsons and Moffat 2014; Thomson and Boutilier 2011) and most importantly the capacity for collaboration (Ansell and Gash 2008; Edelenbos and van Meerkerk 2017; Emerson, Nabatchi, and Balogh 2012; Howlett and Ramesh 2016). Inclusion and diversity of different actors are key normative and instrumental aspects of collaborative governance. The combined power of different participants that 'come to the table' can result in 
success or failure in collaboration (Emerson et al. 2012). However, various actors may not 'come to the table' due to limited motivation, an absence of common ground (Edelenbos and van Meerkerk 2017), and lack of trust (Ansell and Gash 2008; Emerson et al. 2012; Huxham et al. 2000; Leach and Sabatier 2005; Vangen, Hayes, and Cornforth 2015).

Trust occurs when one actor is open and willing to assume a vulnerable position of another actor, each actor has an expectation of the other's behaviour, and each takes the other actor's interests into account (Klijn, Edelenbos, and Steijn 2010). Or as Klijn, Edelenbos, and Steijn (2010: 196) define it "trust can be defined as a stable positive expectation that actor A has (or predicts he has) of the intentions and motives of actor B in refraining from opportunistic behaviour, even if the opportunity arises." Trust is not separate from dialogue and negotiations, however, it is essential for building relationships before key actors are influenced or manipulated by other interests (Ansell and Gash 2008). Trust is an important characteristic of the quality of relationships, enhances the chances for cooperation and stimulates the development of common ground (Edelenbos and van Meerkerk 2017). Social learning is an outcome of gaining trust in the collaborative process (Siddiki, Kim, and Leach 2017) and can be beneficial to all actors involved.

Trust is therefore essential for establishing SLO, in building upon legitimacy, and for producing successful collaboration (Vince 2018). Emerson, Nabatchi, and Balogh (2012: 13) state:

We conceptualize the mechanism by which trust produces such outcomes as an initial pivotal element within the cycle of shared motivation, that is, trust generates mutual understanding, which in turn generates legitimacy and finally commitment. Trust enables people to go beyond their own personal, institutional, and jurisdictional frames of reference and perspectives toward understanding other peoples' interests, needs, values, and constraints.

A powerful, non-state actor that is capable of steering trust is the media (Vince and Haward 2017). They are used by stakeholders to steer decision making and vice versa. The media has moved beyond the lobbyist role in some natural resource debates and has influenced political outcomes and agenda setting (Abbott 2012; Ader 1995; Korthagen and van Meerkerk 2014; McCombs 2013; Schaferhoff et al. 2009). They are not 'neutral information transmitters' (Korthagen and van Meerkerk 2014) and can shape the information they utilize. The media has the ability to influence community views and can affect how industry is scrutinized through social license (Lester 2016). The role of activism has also been changed due to the media, and in particular due to the ease of access to media outlets (Cullen-Knox et al. 2017). Consequently, social license has moved from being a metaphor to a useful tool to bring about policy change (Boutilier et al. 2012). The state relies on the media to maintain 
community acceptance and of its policies, and relationships with industry and third party certifiers.

Industry can also obtain a social license to operate through CSR (Gjølberg 2009). Although social license and CSR concepts are interrelated and overlap there are key differences (Parsons and Moffat 2014). Through social license, communities and consumers can instigate changes to corporate policies and products (Morrison 2014). Industry is, however, ultimately in control of its CSR policies and activities. CSR and socially responsible investment (SRI) have recently become more prevalent in corporate commitments in environmental sustainability (Richardson 2016). SRI integrates social, environmental and ethical concerns and is known as the 'core of shareholder capitalism' (Steurer 2010). Shareholder influence and stock exchange listing can have a positive impact on sustainability practices. Publicly listed companies endure more scrutiny from the public, government and shareholders than as private companies (as can be seen later in the case of Australian aquaculture).

According to Steurer (2013: 391) "new governance and CSR are complementary concepts that both fundamentally reshape the roles of the public and the private sectors in similar directions." CSR can be driven by community support through social license or government regulation (Vince and Hardesty 2016). Industry can use their CSR policies to gain consumer confidence and to demonstrate their commitment to social and environmental issues. The ultimate achievement for industry that is invested in CSR is community as well as shareholder support. CSR policy is further strengthened when industry is partnered with certification schemes. In some cases, the public is more likely to accept a project that is certified by a third party certification organization than one that is not (Auld et al. 2009). However, as the aquaculture case below demonstrates, there can be exceptions. CSR policies are therefore also useful business tools that contribute to sustainability and economic outcomes.

What companies decide to do with regard to their CSR will often be influenced by the way it "interprets and responds to the various license terms" and that by empowering this social license may be a powerful leverage for large corporations (Gunningham 2009: 227). There are, however, negative consequences to CSR policies that do not quite achieve their social or environmental objectives. 'Greenwashing' or in the marine context 'bluewashing' is known to occur where products are marketed as being sustainable but continue to do environmental damage (Gale and Haward 2011). Communities may become resistant to projects and NGOs can utilize these actions to threaten the withdrawal of social license (Owen and Kemp 2013). In other instances, communities decide to give contingent consent where they accept some of the negative consequences resulting from industry activities because the positives are too valuable (Levi 1997; Owen and Kemp 2013). 
Trust is the connecting element and critical condition for success in privatesocial partnerships, whether through social license, CSR, or collaboration. Industry needs to trust the third party certifier and vice versa; shareholders need to trust the industry; and the community needs to trust both the industry and certification organization and scheme. States also require community and industry trust in order to establish overarching regulatory frameworks for industry operations. However, the lack of trust can also result in failure to collaborate in the first place. The following sections on the ASC and the salmonid aquaculture industry in Australia demonstrate that since ASC is a newcomer to the certification process, the broader community is yet to trust it enough to be involved in any collaboration.

\section{CASE STUDY: THE AUSTRALIAN SALMONID INDUSTRY AND THE AQUACULTURE STEWARDSHIP COUNCIL}

\section{The Aquaculture Stewardship Council}

There are numerous certification schemes, many attached to specific ecolabels, that can be applied to aquaculture such as the ISEAL Alliance's Code of Practice for Standard Development (Alliance 2006) and the FAO Technical Guidelines on Aquaculture Certification (FAO 2011). The ASC is an independent, non-profit organization that was established in 2010 through a collaboration of the World Wide Fund for Nature (WWF) and the Sustainable Trade Initiative (IDF) based in the Netherlands. The WWF had a history of involvement in other certification schemes such the Forest Stewardship Council (FSC) and the Marine Stewardship Council (MSC) (Gale and Haward 2011). The FSC, MSC and ASC all operate transnationally and without governmental involvement (Vandergeest and Unno 2012).

The process in establishing the ASC was not without difficulties (Vandergeest and Unno 2012). Upon its launch over 70 international NGOs campaigned against the creation of the scheme accusing WWF of "pandering' to the interests of big business" (World Rainforest Movement 2009). The ASC along with other aquaculture certifiers have been criticized for not considering the environmental costs associated with distribution and/or transportation (Bush et al. 2013) and for undermining state capacity. Moreover, it is argued that these schemes disproportionately focus on "species and environmental issues important to consumer countries" amongst other issues (Campbell et al. 2016).

Certification schemes such as the ASC can make a contribution to sustainability standards but it is argued that they "should be considered one approach among many for steering aquaculture toward sustainable production" (Bush et al. 2013: 1067). Since the ASC is still in its infancy it has the opportunity 
to evolve to address these criticisms and issues. However, there is no doubt that salmon aquaculture operations are and continue to be controversial (see Haward 2016; VanderZwaag 2016). Aquaculture industry operators have used third party certification to address community concerns about environmental sustainability, however, environmental NGOs have often labelled these approaches as 'greenwashing' (Gale and Haward 2011; Richardson 2016).

The ASC aims to be a world leader in aquaculture accreditation and to "transform the world's aquaculture markets" while promoting "the best environmental and social aquaculture performance" (ASC 2012b: 6). Within two years of operation, ASC certified more than one hundred farms and by January 2016 this number had doubled (ASC 2016).

The ASC Standards were created followed guidelines of the ISEAL Alliance the ISEAL Code of Good Practices for Setting Social and Environmental Standard. They aim to be applied globally, covering diverse "types, locations and scales" of aquaculture production systems (ASC 2012a: 7). Each principle is assessed by reference to a set of criteria. The Salmon Standard, for example, requires data on 37 items of farm performance data to be submitted (ASC 2012b Appendix VI: 89-92). The issue of social acceptability of aquaculture operations is addressed through requirements to address environmental and social performance in the standard (ASC 2012b: 88).

At this time, however, actors like the ASC are flourishing in their impact and influence. Importantly, studies have found that consumers (particularly in the US and Europe) are willing to pay more for certified, sustainably grown, socially responsible and welfare labelled food (Grimsrud et al. 2013; Lim et al. 2015; Napolitano, Girolami, and Braghieri 2010; Olesen et al. 2010; Tully and Winer 2014), which provides aquaculture industries the validity and willingness to be certified. In Australia, as the following section demonstrates, marine and aquaculture certification schemes are not well known by consumers and eco-labelling of seafood does not necessarily provide salmonid aquaculture companies a social license to operate.

\section{AUSTRALIAN SALMONID AQUACULTURE}

Aquaculture is increasingly growing in importance across the world providing over half of the world's supply of seafood (Bush et al. 2013) and becoming a major source of employment in both developed and developing countries (FAO 2014). In the grand overview of fisheries production, the Australian salmonid aquaculture sector is relatively small. However, in Australia it is the largest aquaculture industry due to its location in the island state of Tasmania. It is located in Australia's south east region and it has been marketed as being grown in pristine conditions, disease-free and of a premium quality. Tasmania is now the largest Australian producer of fisheries and aquaculture products 
(ABARES 2015) and for a small state, this has immense economic and social significance.

In Tasmania, salmonid farming is widespread around the state with the major operations located in the state's south. The fishery's productivity is influenced by climate, with hot, dry summers and increased water temperatures constraining growth of fish. Atlantic salmon is not a native to Australian waters and many of the issues regarding wild caught versus farmed salmon faced by the aquaculture sector in Northern America or Europe are not relevant to the Tasmanian situation (Haward 2016). The communities located near the salmon farms are varied, with aquaculture operations providing a key base for employment but also the home to many who are not dependent on such employment. The broader Tasmanian community's concerns are focused on the farming practices, and the environmental, social and economic impact of the industry. As a consequence, it has heavily influenced the industry's growth and capabilities (Vince and Haward 2017; Vince 2018). Decisions regarding farming practices, the environmental, social and economic impact of the industry have been scrutinized by local community groups, environmental NGOs and the media.

In Australia, the regulatory framework that governs salmon aquaculture is fragmented and complex (Haward 2015). Salmon farming locations and operations are located under state jurisdiction. However, if an animal species is affected by operations, Commonwealth legislation can come into effect. Local governments administer planning schemes and implement health and building regulations including pollution and noise. These regulations and bylaws are significant in approval of operations of aquaculture facilities including effluent discharge from processing.

Local government is often the primary focus for debates over aquaculture operations. Another key actor in the Tasmanian aquaculture sector is the Marine Farming Review Panel which is an independent body that assesses and approves aquaculture activities in Tasmania. It was established in the early 1990s but in recent years the state government was going to dissolve it as a cost-cutting measure. This decision was overturned due to the number of issues arising about aquaculture practices in Tasmania. In early 2015 concerns were raised by other aquaculture industries including abalone and mussel farmers who claimed that their industries have been damaged by salmon farming effluent and net cleaning waste (ABC News 2015a). A Senate Committee launched an enquiry into Tasmanian Fin Fisheries at the same time. The Tasmanian Salmonid Growers Association that represented the largest Tasmanian salmon company Tassal testified at the inquiry that the environmental impact of the salmon farms was localized. A review commissioned by the Tasmanian Department of Primary Industries, Parks, Water and Environment was presented at the inquiry, supporting the Association's claims 
that there was no scientific evidence to support that the salmon farming practices were affecting the abalone industry (ABC News 2015c; Buxton 2015).

In addition, a three-year scientific study by the University of Tasmania showed that Tassal, "was one of many factors influencing the waterway" in the south (Atkin 2014). Environment Tasmania produced their own scientific report which contradicted the University' findings that found that there were major gaps in environmental management and that all new farm developments need to be stopped (Atkin 2014).

The success of the industry in Tasmania and its rapid expansion has meant that new sites need to be located around the state to facilitate the industry's growth. Local communities in the south of Tasmania in Lady Bay and on the east coast in Okehampton Bay have been divided about the environmental damage that salmonid aquaculture could do to their waterways if relocated there. In each area, the NGO group Environment Tasmania has been on the forefront opposing aquaculture expansion. Their tactics have included using national media outlets to release underwater video footage of environmental damage near salmon pens (Atkin 2014); organizing large protests outside of the Tasmanian parliament with the No Fish Farms in Tasmania's East Coast Waters Group (The Mercury 2017); and a strong social media presence. Numerous media outlets across Australia have released newspaper and television reports favoring $\mathrm{NGO}$ and community groups rather than the salmonid industry position. An hour-long report on the salmon industry on the nation-wide program 4 Corners (Meldrum-Hanna, Balendra, and McDonald 2016) broadcast by the Australian Broadcasting Corporation (ABC) had such an impact on Tassal that its share prices dropped 9 cents within a couple of days after airing and major investor Tribeca Investment Partners sold AUS $\$ 3.78$ million worth of shares (Australian Associated Press 2016).

Yet, in the midst of this controversy are groups within local communities and the broader Tasmanian community that want salmonid farming expansion, that understand the extent of change the industry has undergone, and see the economic potential of such farming for the state of Tasmania. Interestingly the Environment Minister has argued that "community confidence has to be maintained" (Richards 2016). Supporters of the plan argue that the east coast community needs the employment and economic opportunities that a new salmon farm would provide. It is not unusual in the Tasmanian context for contingent consent be given to salmon farms where the communities value economy over environmental impacts (Leith, Ogier, and Haward 2014; Vince and Haward 2017). At the same time the east coast development also involves groups and individuals who value scenic amenity and location and are not dependent on the local economy for their livelihoods. The Bob Brown Foundation which supports these groups and individuals went to the High Court in April 2018 to 
invalidate the approval of the Environment Minister to permit salmon farming in Okehampton Bay; however, the court dismissed the action (Dunlevie 2018).

Even though Tassal became the first aquaculture company in the world to receive full 'gold standard' ASC accreditation for all its sites (ABC News 2015b) and won the Australian Business Award for Sustainability (Hanson 2015) the community has still withheld its SLO. In this case, the NGO and media's ability to steer the broader community's perception of the industry was more powerful than the third-party accreditation. A report by the Australia Institute found in 2017 that 39 percent of mainland Australians have heard of the negative environmental impacts from salmon farming, and as a result, of those 15 percent have stopped purchasing Tasmanian salmon (Minshull and Browne 2017).

Tassal was listed on the Australian Stock Exchange (ASX) in 2003 and now holds 50 percent of the domestic salmon market (ABC News 2015b). Its major Tasmanian competitor, Huon Aquaculture, listed on the ASX in 2014 and is now undergoing ASC certification. Since its listing Tassal has made a substantial effort in the sector to improve sustainability and environmental performance, including increased transparency of operations. Tassal has embraced CSR policy and sustainability reporting (Tassal Group Limited 2014). Huon Aquaculture, too, has focused on environmental performance and has been involved in conflict with Tassal over aquaculture operations in Macquarie Harbour in western Tasmania. It has maintained that it is "confident that Australian consumers will see that Huon salmon is produced safely and sustainably year round" (Morgan 2017). The Acting Chief Executive of Petuna Aquaculture (another salmon aquaculture company based in Tasmania), David Wood, has argued that the industry needs to rebuild "public confidence and trust" again. Since the ASC is new and not well recognized by the broader public in the Australian market, social license can only be gained by mutual trust and support over time (Vince and Haward 2017). Wood has stated that the broader public needs to be educated about the industry and the certification programs. He goes on to say that "people need to understand the process and what's required to actually achieve that certification and recognize it is a global benchmark of best practice" (Morgan 2017).

Shareholder influence and stock exchange listing can have a positive impact on sustainability practices. Publicly listed companies endure more scrutiny from the public, government and shareholders than as private companies. In the case of aquaculture, Vince and Haward (2017) found that their drive to achieve the highest environmental standards correlated with their ASX listing. Their CSR policies demonstrate that their economic strength is tied to environmental and sustainable practices. This has also driven innovations in operations, focusing on reducing environmental impacts and footprint and 
encouraging movement of fish farms to areas further offshore or with less competition from other uses or users (see Froehlich et al. 2017).

Despite the support of WWF and these accreditation schemes, the Tasmanian community is divided. A perceived lack of transparency in environmental monitoring has been criticized by some local community groups, who also have emphasized the potential conflict of interest of the government as a regulator and promoter of the industry. ${ }^{1}$ The Tasmanian government is openly supportive of the salmonid aquaculture industry in Tasmania, but it does not have the capacity to deliver the environmental assessments and standards that the ASC can provide. On August 10, 2017, the Tasmanian government released a new industry plan that banned the development of new fish farms on the east and north coasts of Tasmania. However, it excludes already existing leases such as Okehampton Bay (Richards 2017). The Primary Industries Minister said that "the government recognizes it's time to refresh our approach including our regulatory system to take the industry to the next level" (Richards 2017). This demonstrates that government here is the target of "governance via persuasion" (Murphy-Gregory 2018), changing policy to reflect community concerns but still keeping industry on side. Industry is also at odds with both the Tasmanian and Commonwealth governments with Huon Aquaculture launching legal action against them over mismanagement of existing fish farms on the west coast (Meldrum-Hanna and Balendra 2017).

Some local communities affected (or those potentially affected) and environmental NGOs are still reluctant to provide their social license for further development of salmonid aquaculture expansion. Memories of past practices that damaged the environment have tarnished the industry's reputation and these communities have little faith in or understanding of the new practices. The CEO of Tassal Mark Ryan has stated "I don't know what more that we can do to actually prove to people that we are doing the right thing" (Ryan 2015). The trust required for collaboration with these groups is clearly not there. Interestingly, the ASC itself has done little to engage with the Tasmanian community or to challenge allegations from Environment Tasmania that "discovered ASC auditors failed to report major breaches of standards by Tassal" (Kelly 2017).

Unlike the MSC where scientific assessments have provided legitimacy and credibility (Vince and Haward 2019), ASC has faced difficulties with the use of science to foster greater community support in the case of Australian salmonid aquaculture. Scientific assessments have been scrutinized with other aquaculture fisheries discrediting their data and leading scientific enquires from other non-state actors. In addition, Australian consumers are not influenced by ecolabels as accreditation schemes such as the ASC and MSC are not widely known or recognized by the public (Lee 2009). When communities are 
provided information of ASC accreditation of salmonid aquaculture it does not necessarily sway their influence for or against farming practices or locations.

\section{LESSONS FOR COLLABORATION AND IMPLEMENTATION CHALLENGES}

The Australian aquaculture industry, based in Tasmania, reveals a number of broad lessons about certification, private-social partnerships or hybrid governance, and collaboration. It is clear that lack of trust between some key actors is the common element that is a barrier to successful collaboration. The broader community has substantial power due to its ability to grant or withhold social license with regard to aquaculture activities. NGOs such as the media and environmental groups can influence local and broader community perceptions on these activities despite large efforts by industry to apply environmental and sustainable measures and practices. Social license can be gained through mutual trust and support and this can take time to establish-even when the necessary steps are being taken to acquire that trust.

The private-social partnership is an important aspect of hybrid governance and yet it does not guarantee social license if the community does not give the organization and scheme legitimacy. The challenges for implementation can be found when second class standards or corruption of certifiers can alter a community's ability to trust. Moreover, competing certifiers can undermine existing schemes and lead to their ineffectiveness. Arguably in the Australian case study, the NGOs and the media's influence has been more effective in gaining community support than scientific evidence and third party certification. It is not difficult to see why, when companies in the same industry turn on each other and the state is seen to be 'switching sides.' The Tasmanian community also remembers past acts of environmental mismanagement by the state, and even though they occurred in other sectors, the distrust is often transferred to resource management industries in general. Certifiers (other than ASC) that competing Tasmanian salmonid companies have relationships with are rarely scrutinized by the media or community. This does not mean that they are any more or less trustworthy, or have better standards. Again, this heightens the challenges for implementation of certification schemes in the Australian context.

Interestingly, as Murphy-Gregory (2018) argues, the Tasmanian community based actors are vying for more regulation and bringing the state back into its traditional role, rather than accepting that the highest level of sustainable practices have been accredited by third party certifiers. The state is not necessarily trusted more than a third party certification organization, however, it can be made accountable for its actions. While accountability in government is not always simple to achieve (Ryan and Walsh 2004), it is a process 
the broader community is familiar with-it can elect another government, ensure ministerial responsibility and so on. The state also ensures managerial competences (as outlined by Kekez, Howlett and Ramesh, Chapter 1 and by Cashore, Chapter 10 in this volume), where state regulation and a transparent adjudicative system is required to ensure trust and system level legitimacy of third party certifiers is maintained. While the state removes itself from the decision making processes in private-social relationships, if corrupt or ineffective certification schemes are identified, it can regulate so that relationship is dissolved. Industry accountability, on the other hand, is linked to their CSR policies and shareholder expectations. Industry is also held accountable for their management of these issues through obligations under companies and security legislation. Third party certification organization accountability is more complex (see for example Gulbrandsen and Auld 2016) and perhaps less transparent to the greater public. However, in most instances, the capacity to be accountable and the capacity of the regulatory system are the Achilles Heel of certification (Kekez, Howlett and Ramesh, Chapter 1 in this volume).

The argument that a third party certification organization may be an expert or have the necessary knowledge over government or other groups to assess sustainability practices (Doberstein 2016) does not increase the level of trust. Doberstein (2016) found that diverse knowledge from different actors can transform deliberations and result in productive collaborative governance. However, some level of trust must be acquired to get to that stage. In the case of Australian aquaculture, NGOs and local community groups do not trust the industry and do not accept the certification process as a valid indicator of sustainability practices; and industry and the community do not fully trust the state. Until some compromise occurs, any efforts towards collaborative governance will fail.

Third party certification organizations and schemes have two sets of relationships that must include a level of trust to achieve legitimacy-with industry and with the community. Clearly the relationship with some parts of the community are waning. Industry is utilizing the certification process as part of its marketing strategies, CSR and SRI policies and its commitment to go beyond 'greenwashing or bluewashing' to attain sustainable outcomes. Government regulation can offer regulatory guidelines for environmental sustainability but they rarely result in marketability. Although certification schemes are mandatory, the process of being certified is voluntary (Bernstein and Cashore 2007). Therefore, industry demonstrates its willingness to change its activities rather than being forced to in response to legislation. It is here that hybrid governance challenges and provides opportunities for the actors involved compared with traditional hierarchical governance. 


\section{CONCLUSION}

Hybrid governance arrangements are becoming more prevalent in the management of natural resources, where third party certification and ecolabelling schemes are increasingly providing an incentive to achieve ecologically sustainable practices. These new actors have challenged state and market social mechanisms, giving industry an opportunity to self-regulate rather than rely on state driven incentives. Third party certification emerged from state failure and a belief that the market and consumers are able to address such failures. However, these organizations need to secure the trust of industry and the community to engage in meaningful collaboration. Since the ASC is still relatively new, it needs to work on the trust of the community. Indeed, the example of aquaculture accreditation highlights the issues with collaboration when trust is absent. This form of collaborative failure can be resolved but it requires effort on the part of all stakeholders.

The experiences of certification in Australian salmonid aquaculture highlights the opportunities and challenges of hybrid governance and private-social partnerships. The community's ability to accept or reject market driven initiatives demonstrates that certification, ecolabelling and CSR policies require its consent. The media and NGOs have been able to steer public opinion on aquaculture activities, leaving industry and the state to defend their activities. Trust in the certification process is low and the lack of understanding of the changes required of industry to achieve accreditation is not a deciding factor in establishing this trust. The lack of ASC involvement in the debate with the Tasmanian community has also contributed to this.

With the increasing reliance on aquaculture produce as the source of seafood consumption around the world, the aquaculture sector in Australia is forecast to grow. Managing this growth at sustainable levels can best occur through the coordination of efforts through a hybrid governance approach where communities, markets and the state collaborate. The importance of third party certification organizations and schemes is not to be underestimated as a tool for future aquaculture development. However, organizations and certification schemes such as the ASC will also need to evolve along with the demands of the market and state regulatory measures.

\section{NOTE}

1. The Tasmanian community's distrust of the state and its relationship with industry has a long history. It is particularly tarnished due to decisions made regarding the forestry industry. The Tasmanian government fast tracked the assessment process of a proposed pulp mill in favor of industry support while changing the legislative arrangements to reflect this (see Gale 2008). Gunns Limited, the largest forestry 
company sued twenty environmental activists (White 2005), further damaging the relationship with the community. In response the government enacted anti-protest laws that stop protestors if they are found to be on business premises, or in the case of forestry, near access areas (Smith 2017). 